\title{
La presència ibèrica, romana i tardoromana a les Terres de Ponent. Noves dades sobre el poblament rural del nord-est de l'ager Ilerdensis (Noguera, Pla d'Urgell i Segrià)
}

The Iberian, Roman and late Roman presence in the region of Ponent. New data on the rural population of the northeastern ager Ilerdensis (Noguera, Pla d'Urgell and Segrià)

\section{Montse Baiges Minguella}

Centre de Recerques del Pla d'Urgell Mascançà

Carrer Borràs, 42, E-25142 Bellvís

montse.baimin@gmail.com

\section{Marc Bouzas Sabater}

Universitat de Girona. Laboratori d'Arqueologia, Història Antiga i Prehistòria Carrer Albera, 15 B, E-17003 Girona

marcbouzas@gmail.com

\section{Jaume Puigredon Boixadera}

Carrer Méndez Núñez, 57, 3r B, E-17600 Figueres

jpuigredon@hotmail.com

En aquest treball s'aporten noves dades sobre l'ocupació del nord-est de l'ager Ilerdensis durant els segles III aC - VII dC, a partir d'un conjunt de monedes, objectes metàl-lics i fragments ceràmics recollits als termes municipals de Camarasa, Bellvís, el Poal, Linyola, Menàrguens, Térmens i Vilanova de la Barca. Pertanyen a dotze jaciments nous o poc estudiats, fet que posa en relleu la manca d'estudis sobre aquest territori, que hauria estat molt més poblat del que coneixem actualment, ja que reuneix unes condicions ecològiques ideals per a la vida humana i el desenvolupament de l'agricultura i la ramaderia al llarg de la història.

AGER ILERDENSIS, POBLAMENT RURAL, ASSENTAMENTS IBÈRICS, ASSENTAMENTS ROMANS, ASSENTAMENTS TARDOANTICS 
This paper brings new light on the occupation of the northeastern ager Ilerdensis (Lleida-Lerida) during the 3rd century $\mathrm{BC}$ to 7th century AD through the study of an assemblage of coins, metal objects and ceramic fragments collected in the vicinity of Camarasa, Bellvís, el Poal, Linyola, Menàrguens, Térmens and Vilanova de la Barca. They belong to twelve newly discovered or poorly studied sites, highlighting the lack of research on this area, and the current evidence indicates that it might have been more populated previously thought, as it has ideal ecological conditions for human life and the development of agriculture and animal husbandry throughout history.

\section{KEYWORDS}

AGER ILERDENSIS, RURAL SETTLEMENT, IBERIAN SITES, ROMAN SITES, LATE ANTIQUE SITES

\section{Introducció}

L'article que els presentem a continuació té per objectiu principal donar a conèixer testimonis, fins ara inèdits, del poblament d'espais rurals de les Terres de Ponent en època ibèrica, romana i tardoantiga, que ens han permès la identificació de noves estacions o jaciments arqueològics encara no catalogats o bé poc estudiats de les comarques de la Noguera, el Pla d'Urgell i el Segrià.

El treball parteix de l'estudi d'un conjunt de materials datats entre els segles $\mathrm{III}$ aC i vII dC, i de l'entrecreuament d'aquestes dades amb el context geogràfic, mediambiental i la informació de l'Inventari del Patrimoni Arqueològic de la Direcció General del Patrimoni de la Generalitat de Catalunya (IPAC). Malauradament, com expliquem a continuació, aquests materials no procedeixen d'excavacions arqueològiques sinó de l'espoli sistemàtic i incontrolat del territori.

Malgrat tot, pensem que estudis com el que presentem, sempre amb finalitats científiques, poden contribuir a la delimitació de nous jaciments, a més a més d'incentivar la recerca arqueològica al territori i la protecció del seu patrimoni, sovint desconegut per bona part de la població, la comunitat científica i fins i tot per l'Administració.

En la selecció dels materials estudiats, tan sols s'han tingut en compte les peces de cronologies ibèrica, romana i tardoantiga que no han estat intercanviades amb altres col-leccionistes, ni tampoc comprades. De les monedes, la major part dels objectes metàl-lics i una petita part dels fragments ceràmics se'n coneix la localització precisa d'origen, ja que en el moment del seu espoli va ser registrada amb l'ajuda d'un sistema GPS i coordenades UTM. En canvi, de la resta d'elements metàl-lics i ceràmics solament se'n saben els possibles espais d'origen, que coincideixen amb els punts de recuperació d'altres materials estudiats en aquest article o en publicacions anteriors dels mateixos autors (Baiges et al., 2019, 2021).

Som plenament conscients de la dificultat d'un estudi on els materials presentats provenen de casos d'espoli i, per tant, el seu valor i informació és clarament menor que si haguessin estat recuperats en els seus jaciments i contextos arqueològics. Per aquesta raó, volem expressar taxativament el nostre rebuig davant d'aquest tipus de pràctiques il-legals, que causen un dany irreparable al patrimoni arqueològic del nostre país. Alhora, creiem necessari donar a conèixer els materials recuperats per deixar constància de la 
seva existència, sempre que es faci amb finalitats científiques per ampliar el coneixement d'aquest territori, independentment del seu origen, propietat o estat de conservació, però mai en substitució d'estudis i intervencions arqueològiques per part dels professionals.

\section{L'ager Ilerdensis. Contextualització del territori}

En l'estudi del poblament i el paisatge antics, cal tenir en compte l'extraordinari canvi sofert a la Plana d'Urgell amb la construcció dels Canals d'Urgell i la reconversió dels terrenys de secà a regadiu des de mitjans del segle XIX, que van comportar explanacions i grans moviments de terres. A més, la dessecació d'estanys i llacunes naturals i la supressió de tossals per guanyar terres de conreu van propiciar el canvi de la xarxa hidrogràfica i van esborrar en molts espais qualsevol empremta anterior, dificultant així la identificació, conservació i estudi dels jaciments arqueològics (Pérez, 1990: 90-91; Puche, 1993: 24-25; Baiges i Mercado, 2018: 230).

L'ager Ilerdensis és el territori en època romana amb el centre del poder econòmic, social i polític a la ciutat de Lleida (Segrià), situada en un important nus de comunicacions entre els Pirineus orientals cap a la Gàl-lia, la vall de l'Ebre, la costa mediterrània i l'interior peninsular. Aquesta ciutat, habitada almenys des de finals del segle v aC (Payà et al., 1996: 122), va ser la capital de la Ilergècia amb el nom d'Iltirta, convertida en el municipi romà d'Ilerda (Pérez, 1990: 89; Payà et al., 1996; Gil et al., 2001) i posteriorment seu episcopal visigoda (Pérez, 1990: 123-128; Gil et al., 2001: 178; Brufal, 2013a: 221-222), perdurant com a capital territorial fins avui en dia.

Aquest territori s'estenia al llarg del curs inferior del riu Segre, a ambdues ribes, possiblement ocupant des de la Clamor Amarga, a l'oest, fins a les primeres elevacions de l'altiplà de la Segarra, a l'est; i des de la Serra d'Almenara i la Serra Llarga, al nord, fins a la Serra del Tallat i la Serra de la Llena, al sud (Pérez, 1990: 84, 2009: 229-230; Ferrer et al., 2012: 50). Limitava amb els territoris d'altres civitates que l'envoltaven, totes a més de 50 km: Iesso (Guissona), Aeso (Isona), Sigarra (Prats de Rei), Labitolosa (Puebla de Castro) i Celsa (Velilla de Ebro) (Pérez, 1990: 85-86).

Aquesta àrea és una extensa plana d'entre els 100 i els 600 msnm, i els punts més elevats se situen a les serres que la tanquen. Hidrogràficament pertany a la conca de l'Ebre, i s'estructura en tres rius cabalosos (el Segre, la Noguera Ribagorçana i el Cinca), diversos rius menors i nombroses rieres estacionals. Malgrat les baixes precipitacions i el gran contrast tèrmic del clima mediterrani continental, la regió té diverses zones d'estanys, llacunes, fonts i aqüífers dispersos, més o menys permanents al llarg de l'any, que juntament amb els rius i les rieres creen grans extensions humides i fèrtils per a les activitats agropecuàries i un aprovisionament constant d'aigua per a la població.

El paisatge rural estava densament poblat, especialment a les ribes dels rius, gràcies a les planes d'alts rendiments agrícoles i els tossals amb gran control visual dels entorns (Nogué i Sala, 2008: 336; Mayoral, 2010: 117, 2016: 103), però el dèficit d'estudis arqueo- 
lògics tant del territori com dels jaciments comporta el seu desconeixement majoritari a hores d'ara (Pérez, 1990: 84; Graells, 2010: 45; Brufal, 2013b; Marí i Revilla, 2018a: 104).

Els ilergets van ser protagonistes destacats durant la Segona Guerra Púnica, i resultant del conflicte bèl-lic es coneix el possible campament cartaginès de la Coma (Palau d'Anglesola, Pla d'Urgell) (Giral, 2015).

De l'Ibèric Final s'ha documentat la decadència de la majoria de poblats ibèrics, tant fortificats com no. Els principals oppida eren el Molí d’Espígol (Tornabous, Urgell) (Escala et al., 2017), el Tossal de la Pleta (Asensio et al., 2018) i Gebut (Soses, Segrià) (López et al., 2018), que estructuraven una densa xarxa de poblats com Els Estinclells I (Verdú, Urgell) (Asensio et al., 2016) i Margalef I (Torregrossa, Pla d'Urgell) (Graells, 2010: 45).

La gran majoria dels assentaments ibèrics se situaven al cim de tossals per protegirse i dominar el territori circumdant, però a partir de la reorganització territorial romana del segle I aC s'observa el trasllat dels establiments al pla, just als peus de les elevacions o més propers a la nova xarxa viària (Gil et al., 2001: 174; Pérez, 2009: 237, 239-240; Baiges i Mercado, 2018: 230). El nou poblament rural s'organitzava a partir de les villae, complementades per una munió d'altres establiments agrícoles menors o relacionats amb les calçades (Pérez, 1990: 84, 2009: 231; Marí i Revilla, 2018a: 104). Properes a la ciutat d'Ilerda hi ha indicis de notables villae, com el Romeral (Albesa, Noguera) (Marí i Revilla, 2018a), Torre Andreu (Lleida, Segrià) (Pérez i Rafel, 1993), Raimat (Lleida) (Pérez, 1990: 87; Garcés, 2014), la Fonteta de Grealó (Lleida) (Junyent i Pérez, 1982), villa Fortunatus (Fraga, Baix Cinca) (Martín, 2006), Cantaperdius (Bellvís, Pla d’Urgell) (Marí et al., 1982), el Tossal del Moro (Corbins, Segrià) (Marí i Revilla, 2003), Els Vilans 2 (Aitona, Segrià) (Pérez, 1986), Gebut 2 (Soses, Segrià) (González i Rodríguez, 2009), el Tossal de l'Àliga (les Borges Blanques, Garrigues) (Pérez, 1991), etc.

La majoria de villae van desaparèixer al voltant del segle III, i les poques que subsistien van arribar fins a mitjans del segle v, quan a causa de la inestabilitat política i social es va tendir a petits nuclis autosuficients, alguns de fortificats, situats en tossals o en espais perifèrics d'antigues villae (Baiges, en premsa; Pérez, 2009: 239-240). A l'ager Ilerdensis trobem llogarets i poblats a Bovalar (Seròs, Segrià) (Palol, 1989), el Tossal del Moro (Castellserà, Urgell) (Escala et al., 2011), el Romeral (Albesa, Noguera) (Marí i Revilla, 2018a) i Vilans de Reig (els Torms, Garrigues) (Nieto i Escala, 2004). Al mateix temps, algunes villae van ser reformades i enriquides en les àrees residencials i ampliades en els espais artesanals, com Bonany (Balaguer, Noguera) (Pérez, 2001b: 165) i villa Fortunatus (Fraga, Baix Cinca) (Martín, 2006).

\section{Noves evidències de l'ocupació del territori}

Els dotze punts d'origen dels materials numismàtics, metàl-lics i ceràmics estudiats en aquest treball corresponen a dos jaciments arqueològics catalogats a l'Inventari del Patrimoni Arqueològic de Catalunya (4373 i 16135), dos més publicats recentment per 


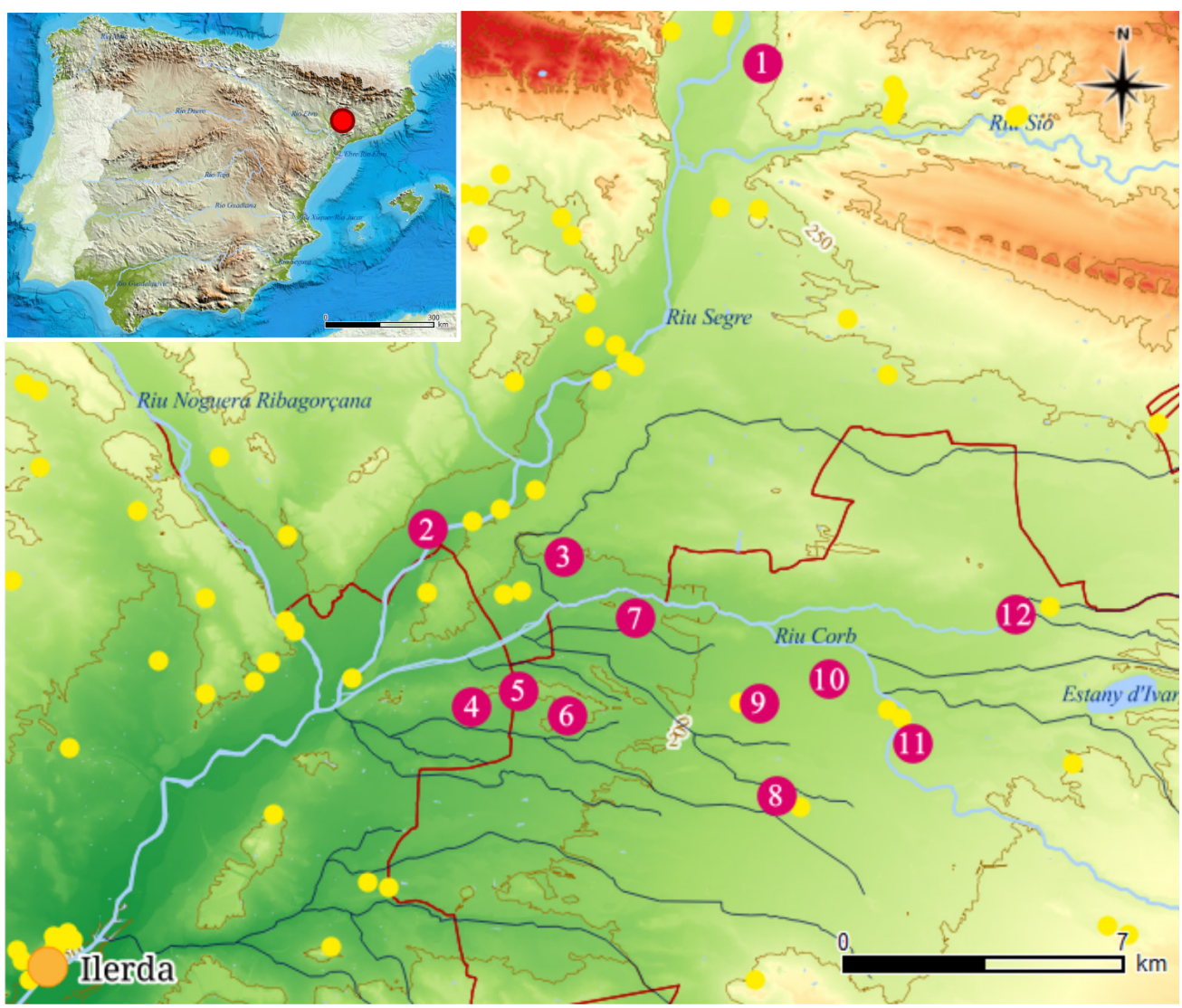

Figura 1. Procedència del material ceràmic, numismàtic i metàllic analitzat, numerada segons l'ordre en el text (rosa), amb relació a la presència humana a l'ager Ilerdensis entre els segles v aC - VII dC (groc) i la ciutat de Lleida (taronja), a més de la seva localització en el marc de la península Ibèrica. Font: elaboració pròpia a partir de la informació del text, els jaciments catalogats a l'Inventari del Patrimoni Arqueològic de Catalunya i les fonts cartogràfiques de l'Institut Cartogràfic i Geològic de Catalunya i el Instituto Geográfico Nacional.

primer cop (Baiges et al., 2019, 2021), i els vuit espais restants són inèdits, ja que no se'n tenia cap notícia històrica anterior (fig. 1). Desconeixem quina era la localització original exacta de les peces dins dels respectius jaciments.

\subsection{Bellona (Camarasa, Noguera)}

Se situa a la riba esquerra del Segre i als voltants del Canal Auxiliar d'Urgell, en una terrassa plana entre la Serra de la Torre Figueres i el Clot d'Antillac (una àmplia i fèrtil zona de bosc de ribera) (Institut Cartogràfic i Geològic de Catalunya, ICGC). En aquest espai, 
on no hi havia constància de cap jaciment arqueològic (IPAC), s'hi ha recollit una unitat ibèrica de la seca de Kelse (fig. 2.1), datada amb certesa al segle II aC, i una unitat d'Iltirta (fig. 2.2), amb un cavall galopant al revers, del 104-80 aC.

A les rodalies hi ha constància de diversos jaciments amb ocupació compresa entre els segles II-I aC, com el Merengue (Camarasa) (IPAC 7278), a la mateixa riba esquerra, i a la dreta del Segre, la Torre Moles (IPAC 7328), la Colomina 2 (IPAC 7329) i Morulls (Gerb, Noguera) (IPAC 7326).

\subsection{Els Quitis (Menàrguens, Noguera)}

A uns 100 metres de la riba dreta del Segre, a la seva terrassa inferior, a dos quilòmetres del nucli urbà de Menàrguens i a 300 metres de l'espai natural de bosc de ribera del Sot del Fuster, s'hi troba el jaciment arqueològic dels Quitis (IPAC 16136), un establiment rural d'època romana, probablement una vil·la dels segles II aC - II dC, actualment cobert per camps de conreu. Malgrat que no s'hi ha dut a terme cap mena d'intervenció arqueològica, ha estat definit geogràficament i cronològicament a partir d'una gran quantitat de fragments ceràmics en superfície, alguns de mides notables, com doliae, tegulae, terra sigillata, ceràmica comuna romana i àmfores itàliques. A més, al seu extrem sud-est s'observen grans amuntegaments de terra, carreus i còdols que, juntament amb les restes d'opus signinum escampades, pertanyerien a les estructures de la possible vil·la (IPAC 16136). A l'interior del jaciment es va recuperar una unitat d'Iltirta (fig. 2.3), amb el típic genet amb palma galopant al revers, datada el 104-80 aC, coincidint amb l'ocupació proposada de l'establiment.

\subsection{Les Roques del Nen (Térmens, Noguera)}

El Tossal de la Figuera és una elevació rocosa situada entre els 200 i 213 msnm i rodejada per la riera del Reguer Petit, i actualment està molt transformada pels camps de conreu abancalats i les granges. A la seva part solana, coneguda també com a Roques del Nen, en un indret on no hi havia constància de restes arqueològiques (IPAC), s'hi va recollir un as de l'emperadriu Faustina I (fig. 2.4), batut a Roma entre els anys 141 i 142 dC.

A l'entorn més proper s'hi han documentat diversos jaciments d'aquest mateix moment, com la necròpolis del Vedat (IPAC 4435), l'assentament de Lo Tossal (IPAC 4433) i el Pla de Violes (Térmens) (IPAC 4430).

\subsection{Tossal del Mussol (Vilanova de la Barca, Segrià)}

És una petita elevació de 2 ha de superfície, fortament modificada pels camps de conreu abancalats i les granges. Domina la riera de les Planes, que passa pel sud del tossal, a uns 20 metres de desnivell, i que proporciona una coma fèrtil regable d'uns 400 metres d'amplada. Tot 
1

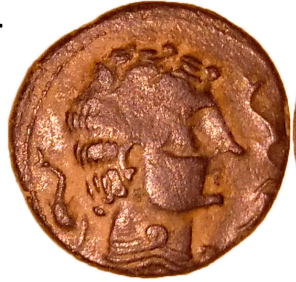

3

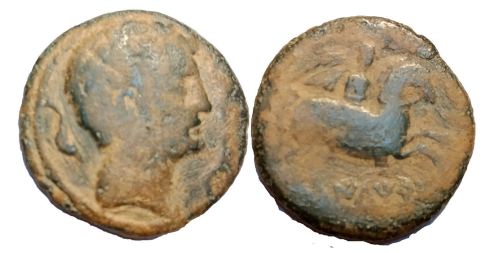

6

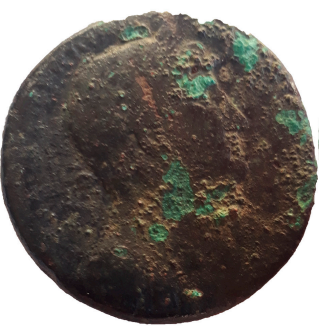

19

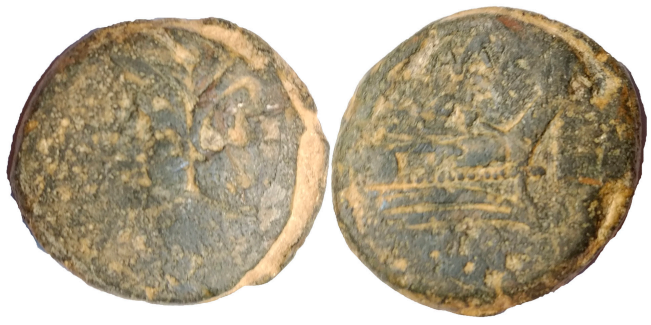

2

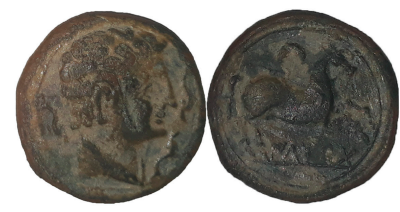

4

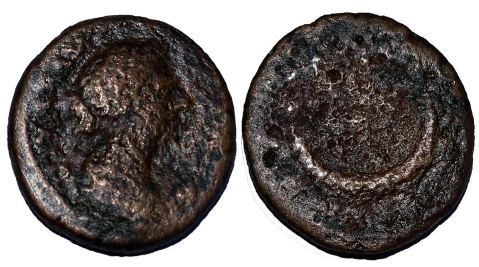

7

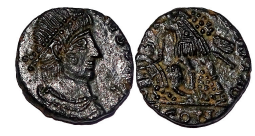

20

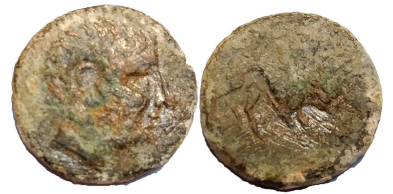

0

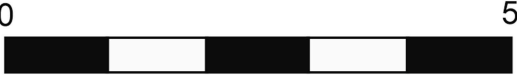

Figura 2. Les monedes. Les peces apareixen referenciades amb el número del catàleg.

i ser un espai on no hi ha constància de restes arqueològiques (IPAC), s'hi ha recuperat un sesterci (fig. 2.6) pràcticament il-legible, que es pot situar al segle II $\mathrm{dC}$ pel pes i la retratística de l'anvers, i un conjunt indeterminat d'individus de ceràmiques romanes d'importació i producció local compreses entre l'època tardorepublicana i el segle II dC (fig. 3 i 4 ).

A més, s'hi ha recollit una fíbula (fig. 5.5) de bronze, en forma de D, amb un nervi al pont (que en ressegueix tota la forma) i un peu curt sense inscripció. És del tipus Avcissa, 
altament conegut a tot l'Imperi i amb paral-lels en tota la seva zona occidental, del tipus 20 del catàleg d'Erice, d'època augustal (Erice, 1995: 119-141), però el mal estat de conservació no permet concretar més sobre la tipologia ni observar-hi cap inscripció. Es coneixen troballes d'aquestes fíbules a diversos llocs de la Península (Erice, 1995: 119-141) i casos similars amb cronologies del segle I dC a Navarra (Mezquíriz, 201 1: 51-52).

A l'entorn més proper es coneixen jaciments de cronologies similars, com el Tossal Roig (Bellvís, Pla d'Urgell) (Baiges et al., 2019, 2021), les Coves (IPAC 12461), el Tossal Roig (Vilanova de la Barca) (IPAC 299) i Lo Tossal (Térmens, Noguera) (IPAC 4433).

\subsection{Tossal de l'Or (Bellvís, Pla d'Urgell - Vilanova de la Barca, Segrià)}

Aquest tossal, d'aproximadament una hectàrea de superfície, configura just el límit entre els termes municipals de Bellvís i Vilanova de la Barca. Actualment és un espai erm arranjat per al gaudi del Pou de l'Or, de principis del segle xx, i al sud del qual s'hi coneix una trinxera de la Guerra Civil que no ha estat excavada (Pera, 2003: 53-62, 2015). En el present estudi s'han pogut estudiar diversos fragments i individus ceràmics d'època ibèrica d'una cronologia compresa entre els segles III i II aC (fig. 4.8-4.12).

Pròxim al jaciment hi ha indicis d'ocupació durant l'Ibèric Final en altres espais com el Tossal Roig i Safareig (Bellvís) (Baiges et al., 2019, 2021), Lo Tossal (IPAC 4433) i la Vinya Vella (Térmens, Noguera) (IPAC 4432).

\subsection{Tossal Roig (Bellvís, Pla d'Urgell)}

És el punt més oriental d'un tossal de gran extensió, de saulons i argiles, situat en els termes de Bellvís i Vilanova de la Barca (Segrià), i fins a la riba del Segre i del Corb; la seva notable superfície, de $7,5 \mathrm{~km}^{2}$, queda reflectida en la toponímia local, dividint-se en subpartides com el Tossal Roig (present a ambdós termes), el Tossal de l'Or (3.5), el Tossal Sabater, el Tossal del Mussol (3.4), la Roca del Quadro, el Tossal Ramon, etc. Segons l'IPAC, en aquesta elevació hi ha documentats els jaciments arqueològics de les Coves (un assentament dels primers segles de la romanització i una necròpolis tardoantiga; IPAC 12461) i el Tossal Camats (un poblat del Bronze Mitjà i Final, amb una ocupació posterior durant l'edat mitjana; IPAC 298).

El Tossal Roig de Bellvís, des dels 210 msnm, controla la riera de les Planes i lo Regueret al sud, que creen una àmplia coma fèrtil, humida i solejada, ideal per a l'agricultura i la ramaderia. Arran de les últimes investigacions efectuades en aquest terme municipal, s'hi ha descobert un assentament ocupat almenys entre els segles II aC i II dC, de l'Ibèric Final a l'alt Imperi romà, però el qual encara no ha pogut ser excavat (Baiges et al., 2019, 2021). D'entre els materials recollits, destaquen una moneda grega de plata d'Emporion, dues 


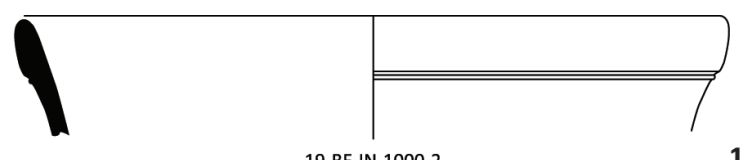

19-BE-IN-1000-2

1

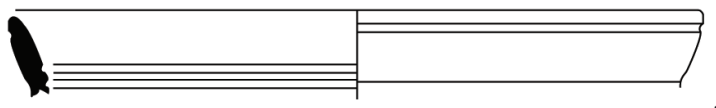

19-BE-IN-1000-3

3

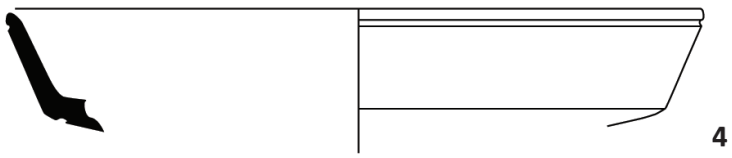

19-BE-IN-1000-4

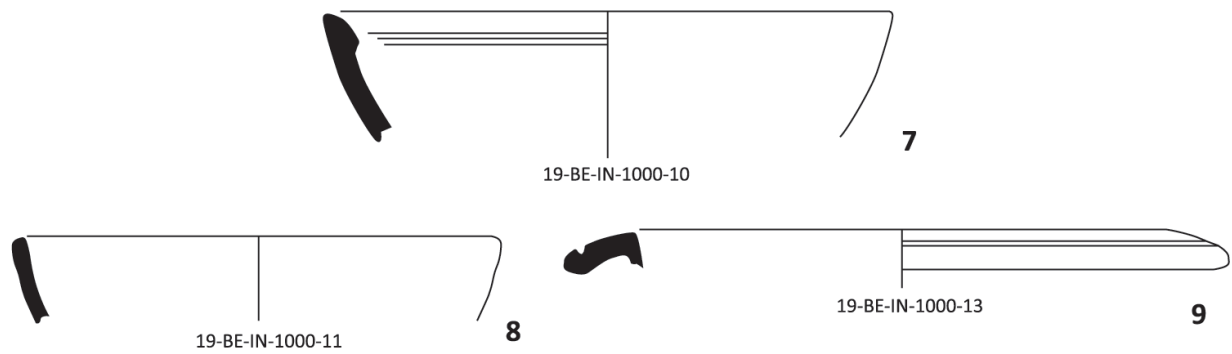

\section{(1)}

19-BE-IN-1000-11

8

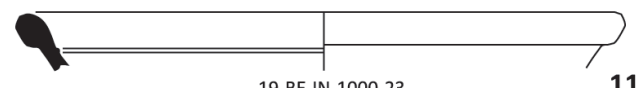

10

19-BE-IN-1000-23

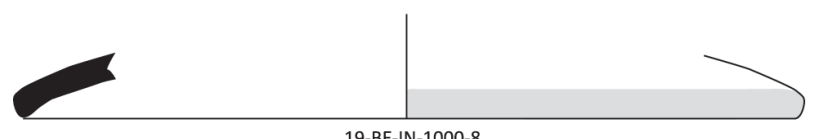

19-BE-IN-1000-8

12

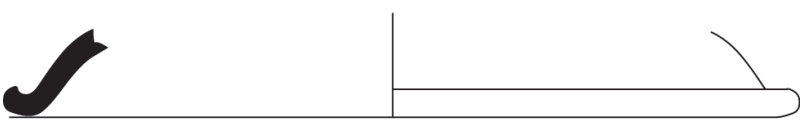

19-BE-IN-1000-22

13
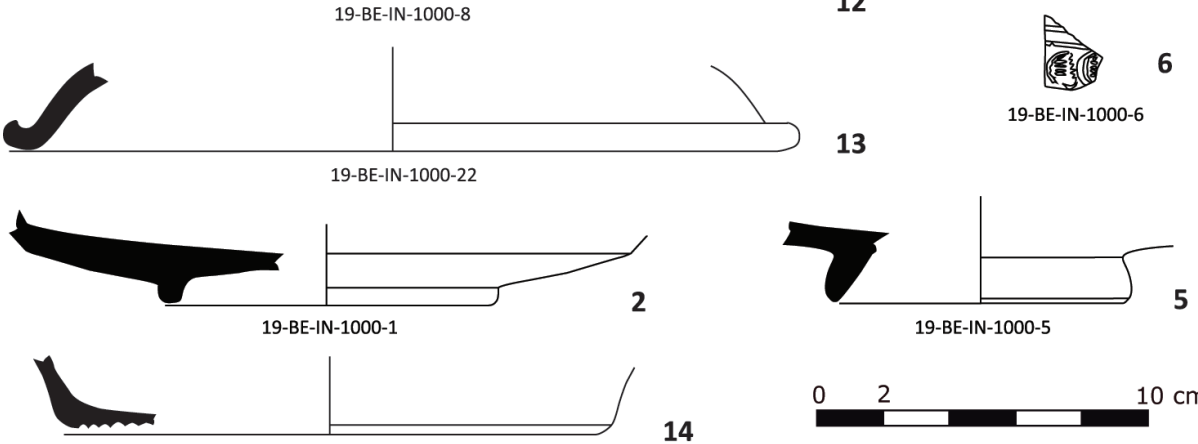

14

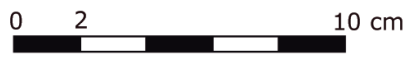

19-BE-IN-1000-9

Figura 3. Ceràmica d'importació (TSI, TSG, Clara A, Clara B, AF-CUIN). 


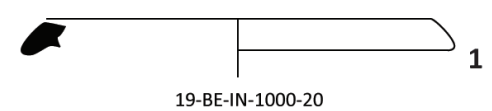

19-BE-IN-1000-20
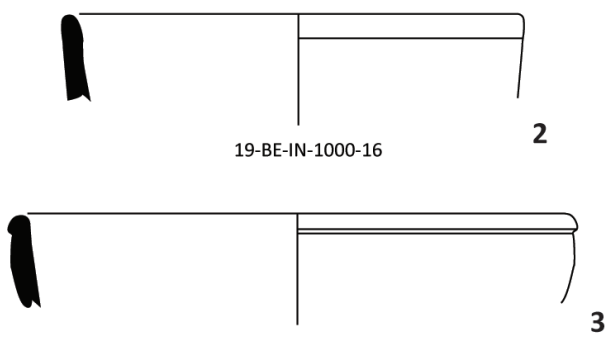

19-BE-IN-1000-17

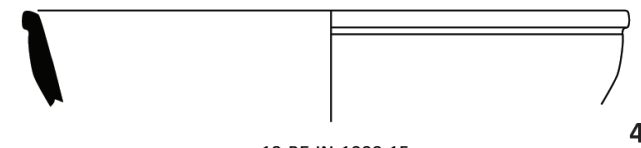

19-BE-IN-1000-15

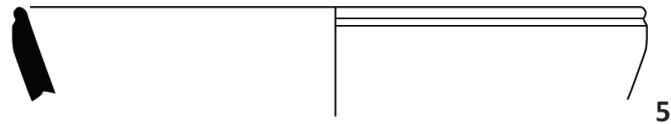

$19-B E-I N-1000-18$

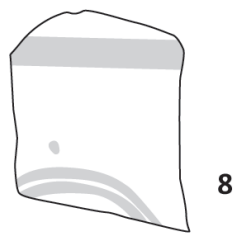

19-BE-IN-1000-35

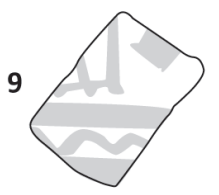

19-BE-IN-1000-34
19-BE-IN-1000-37

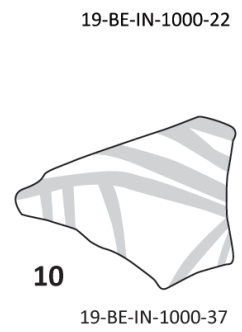

6

19-BE-IN-1000-22

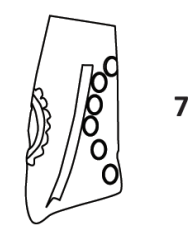

19-BE-IN-1000-21

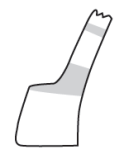

7

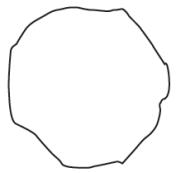

13

19-BE-IN-1000-39

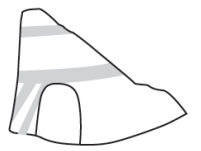

19-BE-IN-1000-33

11
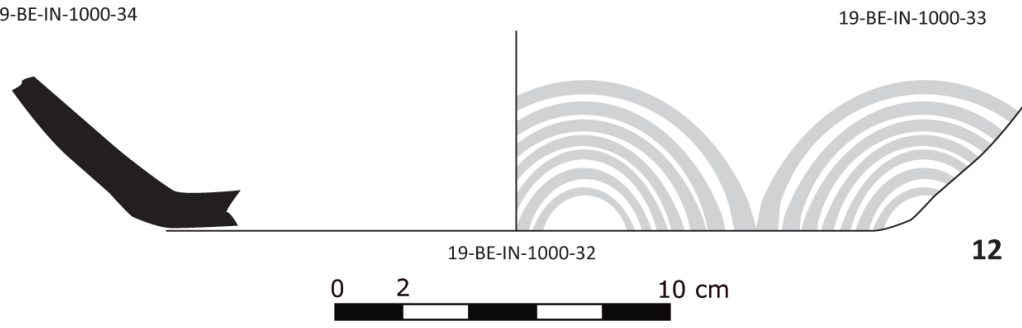

Figura 4. Ceràmiques ibèriques i romanes de producció local (IB-PEIN, COM-IB, TSH, COM). 
monedes de la seca ibèrica d'Iltirta, dues monedes batudes a Roma per l'emperador Antoní Pius i un interessant conjunt ceràmic, que correspon a un context domèstic comprès entre els segles III aC - II dC (fig. 3 i 4), format per un ampli repertori d'individus de ceràmiques ibèriques, campaniana A, terra sigillata sudgàl-lica i hispànica, entre els quals destaca una Drag. 37 del taller d'Ilerda (Baiges et al., 2021: figura 11.2).

\subsection{La Calçada (Bellvís, Pla d'Urgell)}

És una partida ${ }^{1}$ del terme de Bellvís, amb dues lleugeres elevacions del terreny d'entre els 196 i 200 msnm, delimitada al nord pel riu Corb, al sud per la riera de Safareig i a l'oest per la carrerada del poble medieval de Safareig. S'ha proposat l'origen del nom de la partida en una possible via romana que unia Tarraco i Labitolosa, però de la qual no s'han documentat restes arqueològiques a la comarca (Bonales, 2018: 25-26). En el promontori meridional s'hi ha recuperat diversa ceràmica d'època romana, tant d'importació com de producció local, compresa entre els segles I aC - II dC (fig. 3 i 4), i també material numismàtic, com una moneda Ae4 (fig. 2.7) d'Arelate datada als anys 353-358 dC. Mostra un revers molt ben conegut per aquest període, d'un soldat romà llancejant un genet bàrbar caigut i que sol dur la llegenda FEL TEMP REPARATIO, llegible només parcialment en aquesta peça. A més, s'observa part de la marca de seca sota exerg (CON), la disposició de la qual fa suposar que es tracta de la seca d'Arelate; però, en canvi, l'art dels cunys, molt rude, duu a pensar que és una moneda d'imitació i, per tant, la seva cronologia d'emissió es podria allargar fins a principis del segle v. Així doncs, a falta de més estudis, podem apuntar, de manera molt hipotètica, dues ocupacions puntuals de l'espai: la primera, a grans trets, entre els segles III aC i II dC; i la segona, cap a la segona meitat del segle IV o principis del v dC.

D'aquesta cronologia també coneixem altres jaciments propers, com són Cantaperdius (IPAC 3473), el Tossal Roig (Bellvís) (Baiges et al., 2019, 2021), la necròpolis del Vedat (IPAC 4435) i Lo Tossal (Térmens, Noguera) (IPAC 4433).

\subsection{Gatén (Bellvís, Pla d'Urgell)}

Aquesta partida del sud-est de Bellvís està situada entre la riera de les Alzines i lo Regueret i prop de la hipotètica via romana entre Tarraco i Labitolosa (Bonales, 2018: 25-26). Possiblement en relació amb el Tossal de Gatén ${ }^{2}$ hi va haver una ocupació compresa durant l'Ibèric Final (segles III-I aC) i una lleu freqüentació entre finals del segle i i principis del II

1. Porció de terreny d'alguna extensió i designada amb un mateix nom, part del terme pertanyent a un poble (DIEC2). Divisió d'un terme municipal, que engloba diversos camps, segons criteris orogràfics, hidrogràfics i/o històrics, amb un topònim característic per distingir-lo de la resta de partides del terme municipal.

2. Destruït totalment al segle xx per l'extracció de graves, durant la qual es van constatar nombroses restes ceràmiques, òssies i carbonitzades que no van ser documentades, recollides, portades a cap museu ni s'hi va efectuar cap mena d'intervenció arqueològica, segons fonts orals del municipi. 
dC, que coneixem a partir de l'estudi d'un conjunt de monedes espoliades, entre les quals destaquen un tritartemorion emporità, dues unitats ibèriques de plata i bronze de Bolskan i Kese, un as i un sesterci de Trajà (Baiges et al., 2019: 188-189).

A més a més, a raó d'aquest treball hem pogut estudiar altres materials que ens indiquen una ocupació més o menys continuada en aquest espai entre els segles II aC i III dC. Es tracta d'un conjunt d'individus ceràmics d'època ibèrica i romana que es corresponen amb l'esmentada cronologia (fig. 3 i 4); una fíbula, o almenys part de l'arc anular de la peça (fig. 5.8), plausiblement del tipus 13 d'Erice, amb la presència d'espires i un arquejat al final del pont, molt mal conservada i datada al segle a aC (Erice, 1995: 66-70), i un anell circular (fig. 5.9) amb dos petits cargols als extrems, similar al documentat a Anelo (Navarra), d'entre els segles II i III dC (Mezquíriz, 201 1: 57-59).

\subsection{Cantaperdius (Bellvís, Pla d'Urgell)}

Entre els pobles actuals de Bellvís i el Poal, en unes torres, granges i camps conreats a les partides de Cantaperdius i el Pouet, des de l'any 1931 hi ha coneixement d'un jaciment d'època romana corresponent a un establiment rural, probablement una vil.la activa entre els segles I aC i III dC. Les primeres referències sobre aquest jaciment corresponen a estructures de murs estucats, paviments d'opus signinum, monedes, teules, sarcòfags de pedra i ceràmiques d'època altimperial, de les quals no se'n té cap més notícia ni documentació gràfica (Pubill, 1931). A continuació, es van anar succeint tot un seguit de troballes puntuals en superfície, entre les quals destaca un tresoret de monedes d'or i un tambor de columna de marbre (Pita, 1961: 359; Balagué i Balagué, 1986: 41).

Posteriorment, amb la construcció d'una sèquia es va posar al descobert un altre paviment d'opus signinum i un contrapès de pedra d'una premsa d'oli. Tot això, conjuntament amb la fotografia aèria, en la qual s'observaven possibles traces dels seus edificis, va motivar dues campanyes de salvament en les quals es van fer diferents sondejos arqueològics els anys 1982 i 1983, que van permetre dibuixar una imatge més clara del jaciment, tot i que es va localitzar un àmbit perifèric de l'establiment que hauria estat destinat com a escombrera d'alguna de les reformes de l'edifici principal (Marí et al., 1982, 1983).

La troballa amb posterioritat d'un conjunt de monedes fora del recinte catalogat a l'Inventari del Patrimoni Arqueològic de Catalunya, datades entre els segles II aC i IV dC, entre les quals n'hi havia de les seques ibèriques d'Iltirta i Iltirkesken, una estàtera de bronze gal·la, una moneda augustal de Tarraco, una imitació d'un as de Claudi I, un denari de plata de Domicià, un antoninià de Gal-liè i un Ae2 de bronze de Gracià, va permetre ampliar notablement el ventall cronològic d'ocupació i l'àrea de l'establiment (Baiges et al., 2019).

A més a més, també en superfície s'han recuperat altres materials d'època romana d'entre els segles II aC i III dC, com diversos individus ceràmics d'importació i producció local compresos entre els segles I aC - II dC (fig. 3 i 4 ). 
8

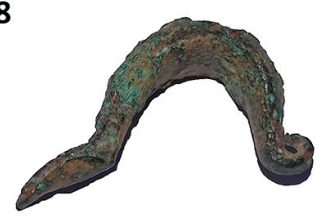

10

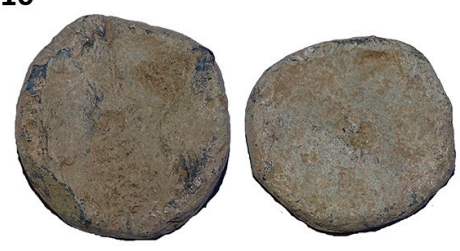

9

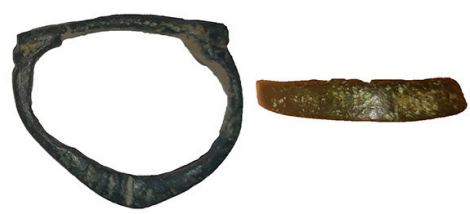

12

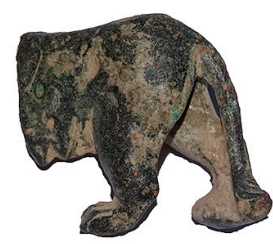

13
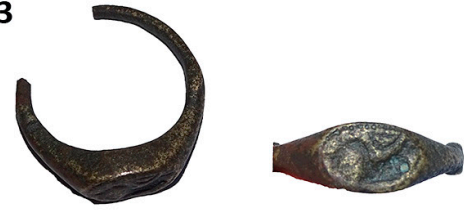

0
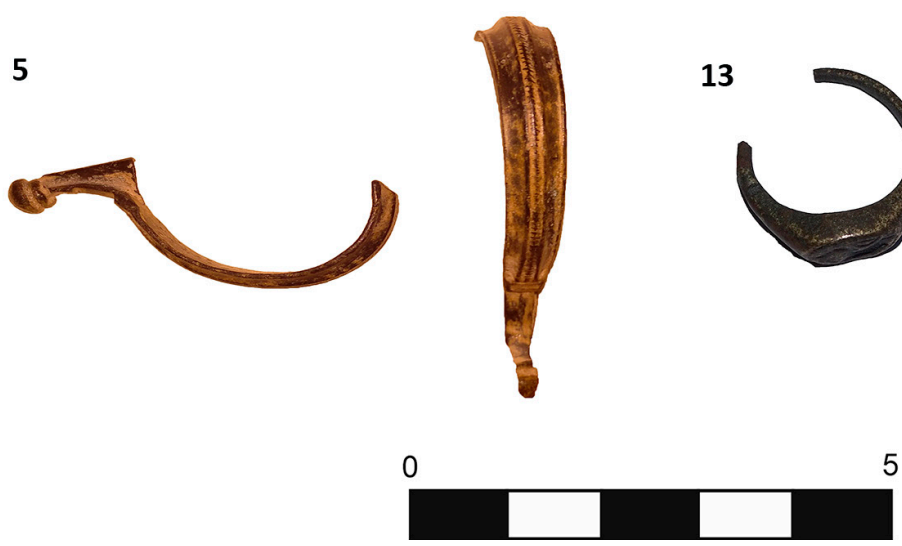

Figura 5. Elements metàl·lics. Les peces apareixen referenciades amb el número del catàleg.

També dos ponderals o pesos de balança; el primer és un pes discoidal (fig. 5.10) de plom, pesa 62,12 grams i se n'ha documentat un paral-lel molt similar al jaciment del Tossal de la Cala (Benidorm) (Grau i Moratalla, 2004: 29), però que malauradament tampoc té context arqueològic, ja que aparentment procedeix de troballes dels anys $40 \mathrm{i}$ es proposa en primer lloc una cronologia d'entre el segle v i el segle I aC, essent teoritzat un ús d'aquest tipus de ponderals entre el segle II i el I aC (Grau i Moratalla, 2004: 33).

El segon ponderal (fig. 6.11) és un pes cònic de bronze de 110 grams, que coincideix (creiem que no casualment) amb un triens de lliura romana (Palol, 1949: 130). Té una gran similitud amb alguns pesos cònics documentats a Segóbriga, especialment els números 22 i 23 (Cebrián i Hortelano, 2017: 201-219), els quals són de menor pes (70 i 80 grams) i classificats com a contrapesos de balança sense mètodes de subjecció, d'època republicana o altimperial (Cebrián i Hortelano, 2017: 213). Ens remetem al cas de Segóbriga com a 

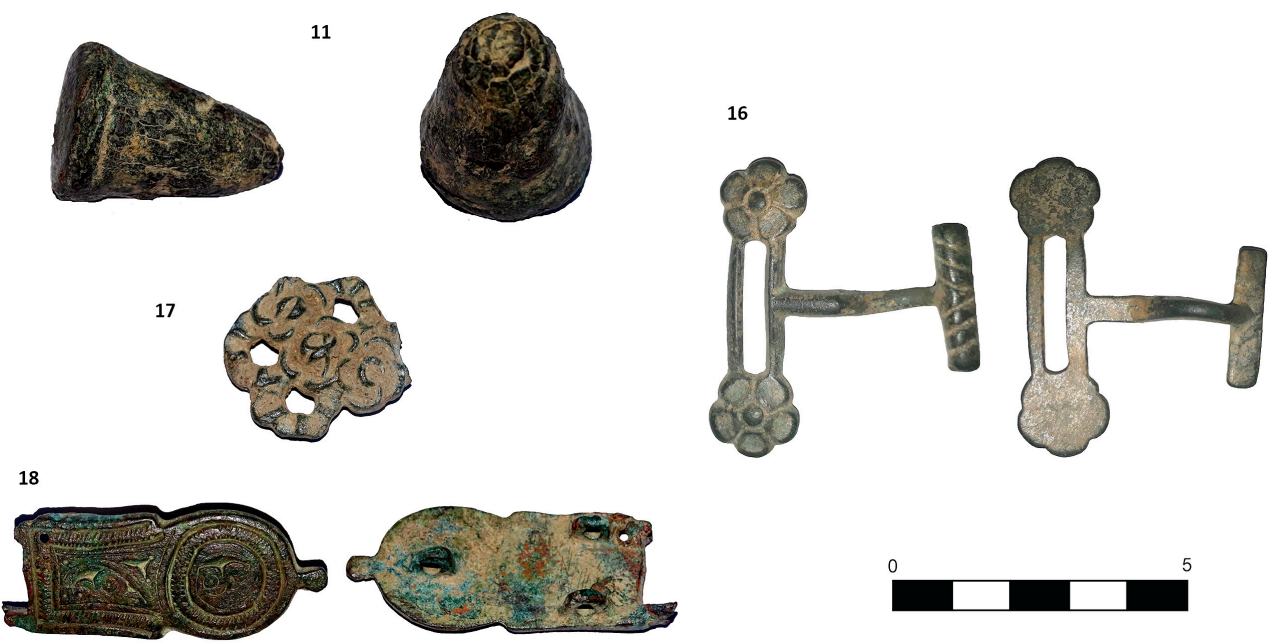

Figura 6. Elements metàl-lics II. Les peces apareixen referenciades amb el número del catàleg.

paral-lel funcional i cronològic (amb un ús continuat en època romana) del ponderal del nostre estudi.

Igualment, s'ha pogut estudiar la part inferior d'un element decoratiu de bronze amb forma de fèlid (fig. 5.12), segurament un lleó, que possiblement fou part de la decoració del mobiliari. El paral-lel més semblant que s'ha pogut trobar es correspon amb aplics de mobiliari dipositats al Museu Arqueològic Nacional de Nàpols, trobats a Pompeia, i per tant amb una datació ben delimitada del segle i dC. Tenint en compte que l'element que estem estudiant està partit per la meitat, poca cosa més se'n pot afirmar, però ens sembla prou rellevant destacar la coneguda predilecció pel lleó o parts del seu cos en el mobiliari romà. En són exemples els elements publicats, entre d'altres, en treballs sobre el mobiliari de Pompeia (Mols, 2008: 149), així com sobre elements de mobiliari general (Pozo, 2005: 431-455; Mezquíriz, 2006: 203).

A més a més, es va recuperar un anell (fig. 5.13) d'un dels tipus més comuns d'època romana, fabricat en coure entre els segles II i III dC, que correspon al tipus 1 de Facsády (Facsády, 2009: 993-998), i semblant en la forma (no en la decoració) al model 1304 del clàssic catàleg de Marshall (Marshall, 1907: 204-205). Aquest anell duia una petita joia o decoració encastada, avui en dia perduda, de la qual només se'n pot apreciar el negatiu.

\subsection{Rubinat (el Poal, Pla d'Urgell)}

Al vessant nord del lleuger promontori on es va edificar el poble del Poal, a uns 500 metres d'aquest i uns 800 del riu Corb, en un espai del qual no es tenia constància de restes 
arqueològiques (IPAC), s'ha documentat una moneda corresponent a un as republicà (fig. 2.19) encunyat a Roma al segle II aC, que presenta el cap de Janus a l'anvers i la recurrent proa de nau al revers.

D'una cronologia similar també es coneixen altres jaciments com Lo Tossal (el Poal) (IPAC 3475), la Cendrosa (Ivars d'Urgell, Pla d'Urgell) (IPAC 1292), El Vilot (Vila-sana, Pla d'Urgell) (IPAC 1288) i el Tossal I (Golmés, Pla d'Urgell) (IPAC 22016).

\subsection{Sarsènit (el Poal, Pla d'Urgell)}

Lleugera elevació del terreny situada a 500 metres del riu Corb per la seva riba esquerra, que rodeja la partida pel sud i l'oest. Malgrat no tenir constància de restes arqueològiques en aquest punt (IPAC), s'hi ha recollit una moneda corresponent a un divisor ibèric (fig. 2.20) de la seca d'Iltirta, amb un llop al revers, d'entre el 80 i el 72 aC.

Immediatament a l'altra riba del Corb s'hi situa el Tossal del Molinet, que dominà aquest espai durant l'Ibèric Ple (IPAC 3476; Junyent i López, 2015). En espais propers també es coneixen els jaciments de Lo Tossal (el Poal) (IPAC 3475), Gatén (Bellvís, Pla d'Urgell) (3.8; Baiges et al., 2019), la Cendrosa (Ivars d'Urgell, Pla d'Urgell) (IPAC 1292), El Vilot (Vila-sana, Pla d'Urgell) (IPAC 1288) i el Tossal I (Golmés, Pla d'Urgell) (IPAC 22016).

\subsection{Pou d'en Savall (Linyola, Pla d'Urgell)}

A la confluència de les rieres d'Almassor i de la Cendrosa, en un pla amb una lleu inclinació cap a l'oest, en un punt sense restes arqueològiques documentades però tan sols a 700 metres de l'establiment romà de la Cendrosa (IPAC 1292), s'hi va recollir un passador en forma de $\mathrm{T}$ (fig. 6.16), amb un espai amb una obertura, decorada a costat i costat amb un senzill motiu floral, pel qual es devia fer passar una peça de roba, probablement una capa o un cinturó ample. Segons els estudis de Pere de Palol, morfològicament resulta molt similar al tipus b de la seva classificació (Palol, 1955: 98).

Aquesta decoració floral es documenta en altres peces, com la pràcticament idèntica de la làmina 4 de l'estudi esmentat (Palol, 1955: 110). Aquest tipus de passadors són poc coneguts, malgrat que se n'han trobat al llarg de la Península amb formes diverses, però mantenint sempre la de T. Es podrien datar sobretot en la baixa època ibèrica, la tardorepública romana i els primers segles de l'alt Imperi (Villaverde, 1993: 404-405).

A les rodalies hi ha constància d'altres jaciments coetanis a aquesta peça, tot i que es troben una mica més allunyats, com el Subcanal (Bellcaire d'Urgell, Noguera) (IPAC 15544), La Serreta (Castellserà, Urgell i Penelles, Noguera) (IPAC 7339), El Vilot (Vilasana, Pla d'Urgell) (IPAC 1288) i Lo Tossal (el Poal, Pla d'Urgell) (IPAC 3475). 


\section{Materials de procedència imprecisa}

A més dels materials anteriors, n’hem estudiat alguns dels quals desconeixem amb exactitud la procedència, tot i que sabem que van ser recollits en els espais de les Roques del Nen (Térmens), el Tossal del Mussol (Vilanova de la Barca), el Tossal de l'Or, el Tossal Roig, la Calçada, Gatén o Cantaperdius (Bellvís).

\subsection{Altres elements metàl·lics}

De procedència dubtosa s'ha tingut ocasió d'estudiar una cadena o un collaret de denes romanes (fig. 6.17), d'entre 30 o 40 baules i uns 18 grams de pes, que actualment es troba compactat en pa, de manera que sense l'acció d'un professional de la restauració no es pot manipular, identificar amb seguretat i tampoc determinar si es tracta efectivament d'un element d'abillament personal o bé de subjecció d'algun altre objecte.

La segona peça és un fermall de tipus liriforme (fig. 6.18), que es pot datar de manera plausible al segle vII (Ripoll, 1998: 168-175). Concretament, aquest fermall es correspon amb una variació del tipus B de la classificació de fermalls liriformes de Ripoll; la peça està dividida només en dues zones diferents, la distal circular i la proximal quadrangular (Ripoll, 1998: 133). Els fermalls liriformes van aparèixer en zones bizantines, concretament al Pont Euxí; possiblement a finals del segle vi i sobretot durant el segle vII ja n'haurien arribat exemplars a la península Ibèrica, i almenys a la zona d'Hispalis se n'hauria iniciat la producció local. Van ser molt presents en tota la geografia peninsular en totes les seves variants (Ripoll, 1998: 168-177), i se n'han trobat en jaciments no gaire distants de la zona estudiada, com el poblat fortificat del Tossal del Moro (Castellserà, Urgell) (IPAC 6641; Escala et al., 2011: 250), la necròpolis del Tossal de Sant Pere (Sant Martí de Riucorb, Urgell) (IPAC 20679) i la necròpolis de Palous (Camarasa, Noguera) (IPAC 15556).

\subsection{El material ceràmic}

Aquest conjunt està format per quaranta-tres individus de cronologia compresa entre els segles III aC i II dC (fig. 3 i 4). Les circumstàncies en què van ser trobats aquests materials fan que no puguin ser tractats com un conjunt arqueològic fiable. Per aquesta raó, hem optat per exposar en forma de catàleg tots aquells materials més representatius als quals s’ha tingut accés, i que s'han pogut identificar a partir de la forma, la decoració, o bé pel taller de procedència.

Així doncs, a partir d'aquests criteris hem establert tres grups diferents segons la seva procedència i funcionalitat: les ceràmiques de tradició ibèrica, les ceràmiques romanes d'importació i les ceràmiques romanes de producció local. 
El primer grup, les ceràmiques de tradició ibèrica, inclou un mínim de set individus. Hi destaquen la presència de quatre fragments informes de ceràmica ibèrica pintada, d'un mínim de tres kalathos diferents, amb decoracions lineals (fig. 4.8-4.10), i dues grans gerres de comuna ibèrica de les formes Jr3 i Jr4, amb decoració lineal de semicercles concèntrics, típicament tardorepublicanes (fig. 4.11-4.12) (Garcés, 2000), a més a més de dues vores d'àmfora ibèrica de les formes R3 i R5.

Les ceràmiques d'importació representen disset individus, entre els quals n'hem distingit dos de terra sigillata itàlica, que són una vora motllurada d'un calze sense decoració de forma R5.1 (fig. 3.1) i una base d'un plat amb peu anular i paret convexa de la forma Consp.4 (fig. 3.2). Els tres individus de terra sigillata sudgàl-lica corresponen a un plat de forma Drag.18 (fig. 3.4), una copa de forma Drag.27 (fig. 3.5) i un bol Drag.29a (fig. 3.3), a més d'un fragment informe amb decoració vegetal d'una Drag.37 del taller de la Graufesenque (fig. 3.6) (Bémont i Jacob, 1968).

Pel que fa a la terra sigillata africana, hem identificat quatre individus de tipus A de les formes 4, 6, 14 i 34 (fig. 3.8-3.11), i un únic individu de B de la forma 15 dels tallers de la vall del Roine (fig. 3.7). A més, quatre individus d'africana de cuina corresponents a una olla Hayes 23 (fig. 3.14) i tres plats tapadora d'Ostia I-261, Ostia I-262, amb la vora fumada, i Ostia II-302 (fig. 3.12-3.13).

Dins d'aquest grup també hem recuperat un gran nombre de fragments informes d'àmfora púnica centremediterrània i púnica ebusitana, i en menor mesura àmfores itàliques de l'àrea vesuviana que no hem pogut associar a cap forma concreta, degut a la falta d'individus.

El tercer grup correspon a les ceràmiques romanes produïdes a la Tarraconense, que representen els vint-i-un individus restants. Entre aquests n'hem identificat vuit de terra sigillata hispànica, corresponents a una Hisp.24/25, una Hisp.35.1, tres Hisp.27 i una Hisp.29 (fig. 4.1-4.5), i dos d'informes, el primer amb decoració metopada i bastant similar als exemplars documentats al jaciment de Cal Montblanc (Albesa), que recorden el repertori decoratiu del taller de Tritium Magallum (Romero, 2015: 192; Marí i Revilla, 2018b: 221), i un segon amb cercles soguers, que recorda molt els motlles de Drag.37 del taller de Bronchales (Romero i Ruiz, 2005: 191) (fig. 4.6-4.7).

No obstant això, davant la impossibilitat de realitzar-ne anàlisis arqueomètriques, en base a l'estudi macroscòpic de les pastes, engalbes i composicions decoratives, aquest conjunt estaria format per peces procedents dels tallers de la Rioja, els tallers de l'ager d'Ilerda i, en menor mesura, per la figlinae aragonesa de Bronchales. Un context que, per procedències, recorda molt el conjunt de sigillata hispànica recuperat a l'establiment rural de Cal Montblanc (Marí i Revilla, 2018b).

La ceràmica comuna oxidada és la menys nombrosa d'aquest grup, amb quatre individus, que es troben representats per un morter de petites dimensions, amb implosions de mica blanca, i dues ampolles, així com dos fragments informes molt polits i curosament retallats, de forma semiesfèrica, que hem identificat com a fitxes de joc (fig. 4.13). També dins d'aquesta categoria hem recollit nou individus de ceràmica de cuina, corresponents a una gran varietat tipològica d'olles fetes a torn, amb el llavi més o menys exvasat, segons la varietat. 


\section{Conclusions}

L'estudi del conjunt de materials presentats en aquest treball evidencia la necessitat d'actualitzar la carta arqueològica i la urgència en la realització de nous estudis sobre l'ocupació del territori i el poblament al nord-est de l'ager Ilerdensis entre l'Ibèric Final i la tardoantiguitat. La descoberta d'aquests nous jaciments i les peces procedents de Cantaperdius i els Quitis demostren, d'una banda, la impunitat amb la qual actuen els detectoristes en aquest territori i, al mateix temps, la manca d'implicació per part de totes les administracions en la defensa i protecció d'aquest patrimoni.

És evident que difícilment a partir de l'estudi dels contextos d'espoli se'n pugui obtenir unes conclusions prou vàlides per modificar la visió que es té actualment del poblament d'aquest territori. No obstant això, considerem que aquesta mena de treballs previs són necessaris per aconseguir que aquest territori sigui posat en valor i estudiat com es mereix, en la mateixa línia que hem anat propugnant en publicacions anteriors (Baiges et al., 2019, 2021).

Resultat d'aquest treball s'han identificat deu nous possibles jaciments arqueològics, compresos entre els segles III aC i VII dC, corresponents a dos establiments rurals actius en època ibèrica i romana al Tossal Roig i a Gatén; un establiment rural d'època romana a la Calçada, actiu entre els segles I aC i II dC, i probablement també durant el baix Imperi o la tardoantiguitat; dues estacions ibèriques indeterminades a Bellona i el Tossal de l'Or; dues estacions d'època romana indeterminades a les Roques del Nen i el Tossal del Mussol, i tres estacions de cronologia i funció indeterminades a Rubinat, Sarsènit i el Pou d'en Savall, dels quals només se'n coneixen un as republicà encunyat a Roma al segle II aC (fig. 2.19), un divisor ibèric de la seca d'Iltirta (fig. 2.20) i un passador en forma de T (fig. 6.16), respectivament.

A més a més, s'han estudiat materials espoliats de dos jaciments ja catalogats per l'IPAC. A la vil·la romana dels Quitis s'hi ha trobat una unitat d'Iltirta (fig. 2.3), que valida la informació recollida a l'IPAC, tant sobre la localització com sobre la cronologia de l'assentament. En canvi, els materials de la vil-la romana de Cantaperdius procedeixen majoritàriament d'espais molt propers però no inclosos dins de l'àrea arqueològica (fig. 5.10, 12, 13 i 6.11), de manera que interpretem que la superfície del jaciment és superior a la que s'estableix a l'IPAC, en concordança amb estudis anteriors (Baiges et al., 2019). Alhora, amplien notablement el ventall cronològic d'ocupació del jaciment segons les intervencions dels anys 1980 (Marí et al., 1982).

Malgrat les limitacions que comporten aquesta mena d'estudis, aquestes evidències demostren que aquest territori estava més densament poblat del que es coneix actualment, degut principalment a un dèficit d'estudis i recerques de llarga durada, ja sigui a jaciments concrets com a unitats d'estudi o el seu territori i la seva interacció dins d'un context més ampli (Pérez, 2009; Graells, 2010: 47; Baiges i Mercado, 2018; Marí i Revilla, 2018a: 124-125).

Tot i això, queden clares les grans oportunitats que oferia aquesta regió als seus habitants per a la implementació de l'agricultura i la ramaderia, que es van beneficiar del 
relleu i la xarxa hidrogràfica. Era un territori eminentment ruralitzat, amb un gran pes de l'artesania, com el taller de producció ceràmica d'Ilerda (Romero, 2015), la fabricació de llànties a Raimat (Garcés, 2014) i el forn ceràmic de Sant Martí de Maldà (Escala et al., 2015). A més, disposava d'una xarxa viària i fluvial que permetia el moviment de persones, idees i mercaderies (Gil et al., 2001), demostrat gràcies a la gran quantitat de monedes recuperades, els productes agraris de les grans explotacions agrícoles, com l'oli de Cantaperdius (Marí et al., 1982), i la importació de ceràmiques fines per al servei de taula de terra sigillata itàlica, sudgàl·lica i africana (fig. 3), així com joies i adorns de luxe (fig. 5.13).

\section{Catàleg de materials}

Abreviatures: CNH = Villaronga, 1994; RIC III = Mattingly i Sydenham, 1930.

1. Unitat de Kelse, mitjans del segle in aC.

Anv.: cap masculí a dreta, amb pentinat original distribuït en línies, rodejat de tres dofins (un darrere el cap i dos davant).

Rev.: genet amb palma galopant a dreta sobre línia. Sota seu, llegenda ibèrica: KELSE.

Bronze; $15,37 \mathrm{~g} ; 27 \mathrm{~mm} ; 3 \mathrm{~h}$.

Ref. bibl.: CNH: 222, n. 9.

Procedència: Bellona (Camarasa).

2. Unitat (o divisor) d'Iltirta, 104-80 aC.

Anv.: cap masculí a dreta, rodejat de tres dofins (un darrere el cap i dos davant).

Rev.: cavall galopant a dreta, per sobre seu un creixent. Sota seu, llegenda ibèrica: ILTIRTA.

Bronze; $5,9 \mathrm{~g} ; 19 \mathrm{~mm} ; 3 \mathrm{~h}$.

Ref. bibl.: CNH: 180, n. 37.

Procedència: Bellona (Camarasa).

3. Unitat d'Iltirta, 104-80 aC.

Anv.: cap masculí a dreta, rodejat de tres dofins (un darrere el cap i dos davant).

Rev.: genet amb palma galopant a dreta. Sota seu, llegenda ibèrica: ILTIRTA.

Bronze; 11,52 g; $23 \mathrm{~mm} ; 3 \mathrm{~h}$.

Ref. bibl.: CNH: 178, n. 22.

Procedència: els Quitis (Menàrguens).

4. Faustina I. As de Roma, 141-142 dC.

Anv.: cap femení a dreta. Llegenda: ...N...

Rev.: creixent rodejat d'estrelles.

Bronze; $9 \mathrm{~g} ; 23 \mathrm{~mm} ; 12 \mathrm{~h}$.
Ref. bibl.: similar a RIC II 1199.

Procedència: Roques del Nen (Térmens).

5. Fíbula Aucissa de pont semicircular en D, segle I dC.

Bronze; 9,26 g; $40 \mathrm{~mm}$ de llargada i $9 \mathrm{~mm}$ d'amplada.

Ref. bibl.: tipus 20 segons la catalogació d'Erice (1995: 138).

Procedència: Tossal del Mussol (Vilanova de la Barca).

6. Sesterci, segle I-II dC.

Anv.: cap masculí a dreta. Llegenda il·legible.

Rev.: il-legible.

Bronze; 23,46 g; $31 \mathrm{~mm}$.

Procedència: Tossal del Mussol (Vilanova de la Barca).

7. Ae4 d'Arelate, 353-358 dC (possible imitació). Anv.: cap masculí diademat a dreta. Llegenda: ...VS...

Rev.: soldat romà llancejant soldat bàrbar caigut a terra. Llegenda: ...PARATIO. Sota exerg: ....CON Bronze; $1,44 \mathrm{~g} ; 12 \mathrm{~mm}$; $6 \mathrm{~h}$.

Observacions: peça possiblement retallada.

Procedència: la Calçada (Bellvís).

8. Fíbula, segle I aC.

Bronze; $5 \mathrm{~g} ; 31 \mathrm{~mm}$ de llargada i $18 \mathrm{~mm}$ d'alçada. Ref. bibl.: tipologia 13 d'Erice (1995: 66-70).

Procedència: Gatén (Bellvís). 
9. Anell, segle II-III dC.

Bronze; $3 \mathrm{~g} ; 24 \mathrm{~mm}$ de diàmetre.

Ref. bibl.: similar als publicats per Mezquíriz, procedents d'Anelo (2011: 57-59).

Procedència: Gatén (Bellvís).

10. Ponderal discoidal, segle II-I aC.

Plom; 62,12 g; $22 \mathrm{~mm}$ de diàmetre i $9 \mathrm{~mm}$ de gruix.

Ref. bibl.: similar als publicats per Grau i Moratalla (2004: 29).

Procedència: Cantaperdius (Bellvís).

11. Ponderal cònic, datació incerta (època republicana o altimperial).

Bronze; $110 \mathrm{~g} ; 40 \mathrm{~mm}$ de diàmetre i $30 \mathrm{~mm}$ d'amplada.

Ref. bibl.: similar als tipus de Segóbriga publicats per Cebrián i Hortelano, n. 22 i 23 (2017: 201-219).

Procedència: Cantaperdius (Bellvís).

12. Escultura d'un fèlid, segle I dC (aproximadament).

Bronze; $29,32 \mathrm{~g} ; 26 \mathrm{~mm}$ de llargada i $25 \mathrm{~mm}$ d'amplada.

Procedència: Cantaperdius.

13. Anell, segle II-III dC.

Coure; 5,25 g; 19 mm de diàmetre.

Ref. bibl.: similar a exemples publicats per Mezquíriz (2011: 59, n. 6). Tipologia lb establerta per Facsády (2009: 997).

Procedència: Cantaperdius (Bellvís).
14. As republicà de Roma, segle $\mathrm{II} \mathrm{aC}$.

Anv.: cap de Janus bifront.

Rev.: proa de nau a dreta. Llegenda: ...MA

Bronze; $37 \mathrm{~g} ; 32 \mathrm{~mm} ; 12 \mathrm{~h}$.

Procedència: Rubinat (el Poal).

15. Divisor ibèric d'Iltirta, 80-72 aC.

Anv.: cap masculí a dreta, rodejat de tres dofins. Rev.: llop a dreta, per sobre seu una estrella.

Bronze; 7,27 g; $18 \mathrm{~mm}$; $12 \mathrm{~h}$.

Ref. bibl.: CNH: 182, n. 49.

Procedència: Sarsènit (el Poal).

16. Passador, segle II aC - I dC.

Bronze; $15,31 \mathrm{~g} ; 51 \mathrm{~mm}$ entre els vèrtexs florals i $41 \mathrm{~mm}$ de l'eix oposat.

Ref. bibl.: similars als publicats per Pere de Palol (1955: 98).

Procedència: Pou d'en Savall (Linyola).

17. Collaret de denes (cadena), època romana.

Bronze; 18,86 g; $32 \mathrm{~mm}$ de llargada i $33 \mathrm{~mm}$ d'amplada.

Observacions: s'aprecien entre 30 i 40 petites baules de bronze d'una cadena, de la qual és impossible determinar si és una subjecció d'algun altre objecte o bé un element d'abillament personal.

Procedència: desconeguda.

18. Fermall de cinturó de tipus liriforme, segle viI. Bronze; 16,00 g; $55 \mathrm{~mm}$ de llargada i $22 \mathrm{~mm}$ d'amplada.

Ref. bibl.: es correspon amb una variació del tipus B de Ripoll (Ripoll, 1998: 133).

Procedència: desconeguda. 


\section{Bibliografia}

ANDREU, J., 2013, Sobre un repertorio de objetos de hueso romanos del Norte de la Tarraconense: Los Bañales de Uncastillo (Zaragoza, España), Habis 44, 115-139.

ASENSIO, D., CARDONA, R., GARCIA, C., MORER, J. i POU, J., 2018, El nucli ibèric del Tossal de la Pleta (Belianes, Urgell), una ciutat ilergeta del segle III aC, Actes de les Primeres Jornades d'Arqueologia i Paleontologia de Ponent. Balaguer i Lleida, 17 i 18 d'abril de 2015, Departament de Cultura de la Generalitat de Catalunya, Lleida, 122-129.

ASENSIO, D., CARDONA, R., MORER, J., POU, J., SAULA, O. i ALONSO, N., 2016, El jaciment dels Estinclells (Verdú, Urgell), una fortalesa ilergeta del segle III aC. Nova recerca a partir del Camp d'Experimentació de la Protohistòria (CEP), Tribuna d'Arqueologia 2013-2014, Departament de Cultura de la Generalitat de Catalunya, Barcelona, 152-176.

BAIGES, M., en premsa, Aproximació al poblament durant la tardoantiguitat a les Terres de Ponent (Lleida, Catalunya), Actas das XII Xornadas de Xuventude en Investigación Arqueolóxica 2019, Cadernos de Arqueoloxía e Patrimonio, INCIPIT - CSIC.

BAIGES, M., BOUZAS, M. i PUIGREDON, J., 2019, L'ocupació del terme de Bellvís en època antiga. Les evidències numismàtiques, Revista d'Arqueologia de Ponent 29, 177-189.

BAIGES, M., BOUZAS, M. i PUIGREDON, J., 2021 , La presència ibèrica i romana a la comarca del Pla d'Urgell. El Tossal Roig (Bellvís, Pla d'Urgell), un nou jaciment arqueològic a les Terres de Ponent, Urtx: revista cultural de l'Urgell 35, 113-131.

BAIGES, M. i MERCADO, R., 2018, Estudi espacial del poblament al curs inferior del riu Corb, Actas XI Jornadas de Jóvenes en Investigación Arqueológica. Tarragona, 9-12 de mayo de 2018, TRAMA 5, Institut Català d'Arqueologia Clàssica, Tarragona, 227-231.
BALAgUÉ, M. i BALAGUÉ, S., 1986, Bellvís, del Tossal de les Sogues al Canal d'Urgell, Offset Romeu, Balaguer.

BÉMONT, C. i JACOB, J., 1968, La terre sigillée gallo-romaine. Lieux de production du Haut Empire : implantations, produits, relations, Documents d'Archéologie Française 6, París.

BLASCO, M., 2016, Dados y fichas de la Edad del Hierro en la Península Ibérica, Archivo de Prehistoria Levantina 31, 241-261.

BONALES, J., 2018, La xarxa viària principal al Pla d'Urgell (segles XI-XVIII), Mascançà: revista d'estudis del Pla d'Urgell 9, 23-31.

BRUFAL, J., 2013a, La medina andalusina de Lleida en el segle xI: Identitat i societat, RiMe. Rivista dell'Istituto di Storia dell'Europa Mediterranea 10, 219-244.

BRUFAL, J., 2013b, El món rural i urbà en la Lleida islàmica (s. XI-XII). Lleida i l'est del districte: Castelldans i el pla del Mascançà, Pagès editors, Lleida.

BUXEDA, J., MADRID, M., MORÁN, M., PAYÀ, X. i PÉREZ, A., 2014, La terra sigillata d'Ilerda, caracterització arqueomètrica i estudi històricarqueològic de la seva producció i de la seva relació amb les ceràmiques engalbades, a $\mathrm{M}$. ROCA, M. MADRID i R. CELIS (eds.), Contextos cerámicos de época altoimperial en el Mediterráneo occidental, Universitat de Barcelona, Barcelona, 182-249.

CEBRIÁN, R. i HORTELANO, I., 2017, Librae, staterae y aequipondia de Segobriga. Instrumentos de pesar hallados en la ciudad y su entorno, Lucentum 36, 201-219.

ERICE, R., 1995, Las fíbulas del Nordeste de la Península Ibérica: siglos I A.E. al IV D.E., Institución Fernando el Católico, Zaragoza.

ESCALA, O., MOYA, A., PIQUÉ, G., PRINCIPAL, J., TARTERA, E. i VIDAL, A., 2017, Darreres intervencions al Molí d'Espígol (Tornabous, Urgell). El projecte de l'1\% cultural: l'excavació arqueològica i els treballs de consolidació i 
restauració del jaciment, Tribuna d'Arqueologia 2014-2015, 267-303.

ESCALA, O., MOYA, A., TARTERA, E., VIDAL, A., ARMENTANO, N. i NOCIAROVA, D., 2015 , La Fogonussa (Sant Martí de Riucorb). Ibers, romans i visigots a la comarca de l'Urgell, Tribuna d'Arqueologia 2012-2013, 244-261.

ESCALA, O., MULET, M. i COLET, A., 2011, El Tossal del Moro. Un jaciment visigot i ibèric a l'Urgell? Primers resultats, Urtx: revista cultural de l'Urgell 25, 243-252.

FACSÁDY, R., 2009, Analysis of Roman Bronze Finger Rings from Aquincum, Materials and Manufacturing Processes 24, 993-998.

FERNÁNDEZ, M. I., 1998, Terra sigillata hispánica: estado actual de la investigación, Universidad de Jaén, Jaén.

FERRER, J., GARCIA, D., MORENO, I., TARRADELL, N. i TURULL, A., 2012, Aportacions al coneixement de la seca ibèrica de śikaŕa i de l'origen del topònim Segarra, Revista d'Arqueologia de Ponent 22, 37-58.

GARCÉS, I., 2000, Les ceràmiques ibèriques pintades tardanes i romanes de tradició indígena a les valls del Segre i Cinca, Revista d'Arqueologia de Ponent 10, 11-38.

GARCÉS, I., 2005, Ilergets i lacetans occidentals: deu anys de recerques i algunes propostes de síntesi, a O. MERCADAL (coord.), Món ibèric als Països Catalans: XIII Col-loqui Internacional d'Arqueologia de Puigcerdà. Homenatge a Josep Barberà $i$ Farràs. Puigcerdà, 14 i 15 de novembre de 2003, Vol. 1, Institut d'Estudis Ceretans, 41 1-440.

GARCÉS, I., 2014, Noves dades sobre l'excavació dels jaciments romans de Raimat (Lleida): un cas singular de gestió del patrimoni arqueològic lleidatà durant el franquisme, Shikar. Revista del Centre d'Estudis Comarcals del Segrià 1, 16-25.

GIL, I., LORIENTE, A., MORÁN, M., PAYÀ, X. i PÉREZ, A., 2001, De la Iltiŕta prerromana a la Ilerda tardorromana. Nuevos datos tras dos décadas de investigación continuada en Lérida, Archivo Español de Arqueología 74, 161-181.
GIRAL, F., 2015, Cartagineses y romanos en la Ilergecia. Testimonios numismáticos, Revista d'Arqueologia de Ponent 25, 83-101.

GONZÁLEZ, A. i MARTÍNEZ, D., 2017, Cuatro hallazgos aislados de dinares epigráficos latinos hispano-musulmanes en Jaén, Documenta $\theta$ Instrumenta 15, 45-56.

GONZÁLEZ, J. R. i RODRÍGUEZ, J. I., 2009, La vil.la romana rústica de Gebut (Soses, Lleida). Estat de la qüestió, a V. REVILLA, J. R. GONZÁLEZ i M. PREVOSTI (eds.), Actes del Simposi: Les vil-les romanes a la Tarraconense. Implantació, evolució $i$ transformació. Estat actual de la investigació del món rural en època romana, Vol. 2, Museu d'Arqueologia de Catalunya, Barcelona, 231-246.

GRAELLS, R., 2010, La recerca arqueològica al Pla d'Urgell: estat de la qüestió, Mascançà: revista d'estudis del Pla d'Urgell 1, 43-50.

GRAU, I. i MORATALLA, J., 2004, La regulación del peso en la Contestania ibérica. Contribución al estudio formal y metrológico de las pesas de balanza, Anales de Prehistoria y Arqueología 19-20, 25-54.

HAYES, J. W., 1972, Late Roman pottery. A catalogue of Roman fine wares, British School at Rome, Londres.

JUNYENT, E. i LÓPEZ, J. B., 2015, Les excavacions dels anys 1973-1974 i 1980 al Tossal del Molinet (el Poal, Pla d'Urgell): una aldea de la primera edat del ferro i època ibèrica, Mascançà: revista d'estudis del Pla d'Urgell 6, 73-98.

JUNYENT, E. i PÉREZ, A., 1982, El yacimiento romano de la Fonteta de Grealó (Lleida, Segrià), Ilerda 43, 63-93.

LÓPEZ, J. B., ALONSO, N., BERNAL, J., CASTELLANO, A., GONZÁLEZ, S., MARTÍNEZ, J., MOYA, A., OLIVA, J. A., PRATS, G., TARONGI, M. i VILA, S., 2018, L'oppidum ibèric de Gebut (Soses, Segrià): avanç dels resultats de la campanya d'excavacions 2017, Revista d'Arqueologia de Ponent 28, 247-282.

MARÍ, L., MASCORT, M. T. i SANMARTÍ, J., 1982, La vil-la romana de Cantaperdius (Bellvís La Noguera), Ilerda 43, 95-117. 
MARÍ, L., MASCORT, M. T. i SANMARTÍ, J., 1983, Cantaperdius (Bellvís, Pla d'Urgell). Memòria definitiva. Campanyes 1982 i 1983 [en línia], Direcció General del Patrimoni Cultural del Departament de Cultura i Mitjans de Comunicació, Barcelona. Consulta: 3 de gener de 2019. Disponible a <http://hdl.handle.net/10687/8062>.

MARÍ, L. i REVILLA, V., 2003, El Tossal del Moro (Corbins, Segrià). Economia i organització de l'espai en una vil.la del territori d'Ilerda, Actes de les jornades d'arqueologia i paleontologia 2000. Comarques de Lleida. Lleida, 30 novembre - 1 i 2 desembre de 2000, Departament de Cultura de la Generalitat de Catalunya, Barcelona, 343-361.

MARÍ, L. i REVILLA, V., 2018a, Arquitectura i hàbitat al territori d'Ilerda: la vil-la del Romeral (Albesa, la Noguera) entre els segles I i vi dC, Revista d'Arqueologia de Ponent 28, 103-129.

MARÍ, L. i REVILLA, V., 2018b, Cultura material y cultura escrita en la sociedad rural de Hispania en los siglos I-II d. C.: el conjunto cerámico y los grafitos del asentamiento de Cal Montblanc (Albesa, Lleida), Archivo Español de Arqueología 91, 217-242.

MARSHALL, F., 1907, Catalogue of the Finger Rings, Greek, Etruscan and Roman, in the Department of Antiquities, British Museum, British Museum, Londres.

MARTíN, L., 2006, Los conjuntos arqueológicos de El Bovalar (Serós, Lleida) y Villa Fortunatus (Fraga, Huesca). Estudio en el contexto de la organización territorial del Bajo Segre-Cinca en épocas bajoimperial y visigoda (tesi doctoral), Universitat de Lleida.

MATA, C., 1992, La cerámica ibérica: ensayo de tipología, Estudios de arqueología ibérica y romana. Homenaje a Enrique Pla Ballester, Diputación Provincial de Valencia, València, 117-173.

MATTINGLY, H. i SYDENHAM, E., 1930, The Roman Imperial Coinage. Vol. 3: Antoninus Pius to Commodus (138-192), Spink \& Son Ltd., Londres.

MAYORAL, A., 2010, Els paleocanals de la Plana d'Urgell: un patrimoni a conservar, Mascançà: revista d'estudis del Pla d'Urgell 1, 117-124.

MAYORAL, A., 2016, Biologia de les aigües corrents carbonatades de la Plana d'Urgell, Mascançà: revista d'estudis del Pla d'Urgell 7, 103-114.
MEZQUíRIZ, M., 2006, Apliques decorativos en bronce, procedentes de yacimientos romanos en Navarra, Cuadernos de Arqueología de la Universidad de Navarra 14, 199-206.

MEZQUíRIZ, M., 2011, Catálogo de bronces romanos recuperados en el territorio de Navarra, Trabajos de Arqueología de Navarra (TAN) 23, 21-118.

MOLS, S., 2008, Ancient roman household furniture and its use: from Herculaneum to the Rhine, Anales de Prehistoria y Arqueología 23-24, 145-160.

NIETO, A. i ESCALA, O., 2004, Vilans de Reig (els Torms, les Garrigues): un assentament rural del segle vII dC, Revista d'Arqueologia de Ponent 14, 275-286.

NOGUÉ, J. i SALA, P. (dir.), 2008, Catàleg de paisatge de les Terres de Lleida, Volum 2b, Observatori del Paisatge de Catalunya.

PALOL, P. de, 1949, Ponderales y exagia romanobizantinos en España, Ampurias 11, 125150.

PALOL, P. de, 1955, Pasadores en T, iberorromanos, en la Península Ibérica, Ampurias 17, 97-110.

PALOL, P. de, 1989, El Bovalar (Seròs, Segrià). Conjunt d'època paleocristiana i visigòtica, Diputació de Lleida, Lleida.

PAYÀ, X., GIL, I., LORIENTE, A., LAFUENTE, A. i MORÁN, M., 1996, Evolució espacial i cronològica de l'antiga ciutat d'Ilerda, Revista d'Arqueologia de Ponent 6, 119-149.

PERA, R., 2003, El Pou de l'Or. 10è Aniversari 1993/2003, Associació de dones Pou de l'Or de Bellvís i els Arcs.

PERA, R., 2015, Història escrita i gràfica del procés de recuperació i arranjament del Pou de l'Or. Maig de 2004-maig de 2015, Associació de dones Pou de l’Or de Bellvís i els Arcs.

PÉREZ, A., 1986, El yacimiento romano de Els Vilans (Aitona) y su cronología, Ilerda 47, 101-123. 
PÉREZ, A., 1990, Lleida romana, Pagès editors, Lleida.

PÉREZ, A., 1991, El jaciment romà del Tossal de l'Àliga (Les Borges Blanques, Les Garrigues), Quaderns d'Arqueologia del Grup de Recerques de La Femosa 6, Agrupació Cultural La Femosa, Artesa de Lleida.

PÉREZ, A., 2001a, La Noguera romana, a J. GIRALT (coord.), La Noguera antiga. Des dels primers pobladors fins als visigots, Museu d'Arqueologia de Catalunya, Museu de la Noguera i Ajuntament de Balaguer, 138-159.

PÉREZ, A., 2001b, El Baix Imperi, a J. GIRALT (coord.), La Noguera antiga. Des dels primers pobladors fins als visigots, Museu d'Arqueologia de Catalunya, Museu de la Noguera i Ajuntament de Balaguer, 160-167.

PÉREZ, A., 2009, La zona de la confluencia EbroSegre-Cinca, a V. REVILLA, J. R. GONZÁLEZ i M. PREVOSTI (eds.), Actes del Simposi: Les vil.les romanes a la Tarraconense. Implantació, evolució $i$ transformació. Estat actual de la investigació del món rural en època romana, Vol. 1, Museu d'Arqueologia de Catalunya, Barcelona, 229-242.

PÉREZ, A. i RAFEL, N., 1993, La vil-la romana de Torre Andreu (La Bordeta, Lleida). Un establiment suburbà dels segles II-III $d C$, Monografies d'Arqueologia Urbana 5, Universitat de Lleida, Lleida.

PITA, R., 1961, Notas de arqueología de Cataluña y Baleares. Lérida, Ampurias 22-23, 355-361.

POZO, S. F., 2005, Bronces romanos de Aratispi (Villanueva de Cauche-Antequera, Málaga). Notas sobre la vajilla y el mobiliario doméstico romano, Mainake 26, 431-455.

PUBILL, S., 1931, Les noves estacions prehistòriques, Memòria del Centre Excursionista Balaguerí, Any II, 3, 13-15.

PUCHE, J. M., 1993, Evolució del poblament i relacions macroespacials durant l'edat del bronze a l'Urgell, Revista d'Arqueologia de Ponent 3, 21-64.

RIPOLL, G., 1998, Toréutica de la Bética (siglos vI $y$ VII d. C.), Reial Acadèmia de Bones Lletres, Series Maior 4, Barcelona.

ROMERO, M. V., 2015, La terra sigillata hispánica: producciones del área septentrional, a C. FERNÁNDEZ, A. MORILLO i M. ZARZALEJOS (eds.), Manual de cerámica romana II. Cerámicas romanas de época altoimperial en Hispania. Importación y producción, Museo Arqueológico Regional de la Comunidad de Madrid, Colegio Oficial de Doctores y Licenciados en Filosofía y Letras y en Ciencias, Sección de Arqueología, Alcalá de Henares, 149-230.

ROMERO, M. V. i RUIZ, P., 2005, Los centros de producción de T.H.S. en la zona septentrional de la Península Ibérica, a M. ROCA i M. I. FERNÁNDEZ (eds.), Introducción al estudio de la cerámica romana. Una breve guía de referencia, Servicio de Publicaciones de la Universidad de Málaga, Màlaga, 183-224.

TREMOLEDA, J., CASTANYER, P., FERRER, A. i SIMON, J., 2017, La bòbila romana d'Ermedàs (Cornellà del Terri). Una indústria de producció ceràmica d'època romana al Pla de l'Estany, Grup de Recerca Arqueològica del Pla de l'Estany, Cornellà del Terri.

VILLARONGA, L., 1994, Corpus nummum Hispaniae ante Augusti aetatem, José A. Herrero, Madrid.

VILLAVERDE, N., 1993, A propósito de unos pasadores en forma de «T» iberorromanos localizados en Carteia (San Roque, Cádiz) y en Septem Fratres (Ceuta), Espacio, Tiempo y Forma, Serie II, 6, 399-418.

Inventari del Patrimoni Arqueològic de Catalunya [en línia], Servei de Patrimoni de la Generalitat de Catalunya. Consulta: 15 d'agost de 2019. Disponible $\mathrm{a}<\mathrm{http} / / /$ invarque.cultura.gencat.cat/ $>$. 